\title{
CORRELAÇÕES ENTRE O CROSS-CULTURAL DESIGN E A MODA
}

\section{CORRELATIONS BETWEEN CROSS-CULTURAL DESIGN AND FASHION}

\section{Paola Zambon Azevedo', Carla Pantoja Giuliano²}

Recebido em: 12 de maio de 2017

Aprovado em: 28 de junho de 2017

Sistema de Avaliação: Double Blind Review

\begin{tabular}{l|l|l|l|l} 
RPR & a. 14 & v. 2 & p. $99-112$ & jul./dez. 2017
\end{tabular}

\section{RESUMO}

A temática do Cross-Cultural Design ganha destaque no meio acadêmico ao se observar que fatores culturais, frente à globalização, devem ser atendidos no desenvolvimento de novos produtos. O CrossCultural Design emerge como uma ferramenta de auxílio aos designers na concepção de artefatos que atentem à multiplicidade das culturas, respeitando e considerando aspectos de sentido primordial para os consumidores, sejam eles locais ou globais. Neste contexto, o presente artigo visa correlacionar a abordagem do Cross-Cultural Design com a área da Moda, apontando novas possibilidades de uso deste conceito em um amplo campo de estudo ainda não explorado pelo meio acadêmico. Como estrutura, este artigo apresenta inicialmente um capítulo destinado a contextualização do termo Cultura. Em um segundo momento, tem-se por objeto a Moda, conceituando-a e demonstrando suas origens e instâncias. A posteriori, a temática do Cross-Cultural Design é exposta, na qual abordam-se concepções fundamentais para a construção do termo e seus significados. Em sequência, disserta-se sobre as aplicações do Cross-Cultural Design na projetação de produtos, relacionando-os ao desenvolvimento de produtos de moda. Por fim, apresentam-se as considerações finais, expondo as conclusões obtidas após a compilação deste estudo.

Palavras-chave: Cultura. Design de Moda. Cross-Cultural Design.

\begin{abstract}
The theme of Cross-Cultural Design increases its reputation in the academic environment when it recognizes that cultural factors, in the face of globalization, should be attended in the development of new products. The Cross-Cultural Design arises as a tool to assist designers in designing products that focuses on the multiplicity of cultures, respecting and considering fundamental aspects for the customer, whether local or global. In this context, this present paper proposes to correlate the approach of CrossCultural Design with the Fashion Area, pointing out new possibilities of use from this concept in a wide field of study, although not explored yet by the academic environment. In its structure, this paper initially introduces a chapter intended to contextualize the concept Culture. In a second moment, Fashion is the subject of this paper, conceptualizing it and demonstrating its origins and its instances. A posteriori, the theme of Cross-Cultural Design is exposed, in which fundamental concepts are addressed for the development of the subject and its meanings. In sequence, this paper addresses the Cross-Cultural Design applications in the design of products, in the scope of fashion products development. Finally, the final considerations are presented, disclosing the conclusions obtained after the compilation of this study.
\end{abstract}

Keywords: Culture. Fashion Design. Cross-Cultural Design.

\footnotetext{
${ }^{1}$ Mestre em Design pelo Centro Universitário Ritter dos Reis (Porto Alegre/Brasil). E-mail: paola.zbzambon@gmail.com.

${ }^{2}$ Doutora em Desenho Industrial pelo Politecnico di Milano (Milão/Itália). Professora no Centro Universitário Ritter dos Reis (Porto Alegre/Brasil). E-mail: carla_giuliano@uniritter.edu.br.
} 


\section{INTRODUÇÃO}

Renomados estudiosos que se ocupam em investigar novos cenários globais, tais como Zygmunt Bauman e Ezio Manzini, referem-se a uma liquefação da era moderna e de uma subsequente segunda modernidade, frágil e difusa, de contornos ainda imprevisíveis. Em meio a esse período inconstante, ocorre a difusão de conhecimentos antes rígidos e considerados como sistematizados pelas comunidades de referência, provocando então, novas possibilidades e novos desafios em campos de conhecimento distintos, locais esses em que o design está incluído (MORAES, 2009).

O mundo está transformando-se e o design também se encontra em fase de transição, no qual é possível observar grandes mudanças em seus horizontes de atuação e nos seus instrumentos de uso (MANZINI; MERONI, 2009).

Nos últimos anos pôde-se notar o aumento da demanda por produtos autóctones e a valorização da arte regional, com o referencial histórico local sendo materializado nos artefatos. Em paralelo, há o ressurgimento do artesanato como meio de produção possível, demonstrando novas relações entre o local e o global nos processos de globalização. Essas modificações atuais encaminham produtores e designers a estabelecerem uma nova postura no momento de concepção de novos produtos e serviços, ampliando o foco da atividade do projeto para a cultura projetual, da tecnologia para a cultura tecnológica, da produção para a cultura produtiva. Essas novas exigências são consequências de um mundo que se encontra saturado de mercadorias descartáveis e que agora se depara com um limite não mais aceitável (MORAES, 2009).

Frente a globalização, a autora Sun (2012) questiona como uma tecnologia pode ser concebida com o intuito de se tornar utilizável e significativa para pessoas de diferentes grupos culturais. Indaga ainda de que forma se insere a subjetividade cultural, local e individual em um projeto que contenha um apelo de design para um contexto local, mas sem estereotipar diretamente a cultura. Para a autora, esses são desafios que incitam pesquisadores e profissionais a desenvolverem abordagens mais eficazes no momento de projetarem seus produtos.

Estas considerações a respeito das novas inquietações do campo do design advindas com a globalização vêm ao encontro do tema central deste estudo, o Cross-Cultural Design, que corrobora na compreensão de diretrizes para se estabelecer novos caminhos e soluções para profissionais e pesquisadores da área.

O Cross-Cultural Design pode proporcionar aos designers uma referência valiosa para a geração de inovação com sucesso no mercado global. Trata-se de um processo de repensar ou rever características culturais, redefinindo-os, a fim de projetar um produto inovador para a sociedade, bem como, de promover a singularidade de uma cultura local no mercado global (HO et al., 1996 apud LIN, 2007).

$\mathrm{Na}$ área do design, o projetar características locais em produtos parece ser cada vez mais importante para o mercado global, onde os produtos estão perdendo a sua identidade por causa das semelhanças na forma e na função (GIULIANO, 2015). Neste contexto, o campo da moda pode ser abordado, quando verifica-se que ela é hoje um empreendimento global que transpõem as fronteiras étnicas e de classes (JONES, 2005).

A globalização, que massificou os produtos e as populações com o contato mútuo entre as diferentes sociedades e culturas, hoje, participa de um movimento de inversão, onde a estandardização substituiu-se pela desestandardização. A recusa das ditaduras, o fim de modelos e de padrões vão ao encontro da reivindicação dos consumidores por mais individualidade e poder frente às proposições modernas (CIDREIRA, 2005). 
Neste ínterim, o conceito do Cross-Cultural Design emerge como uma ferramenta de auxílio aos designers na concepção de produtos que atentem à multiplicidade das culturas, respeitando e considerando aspectos de sentido primordial para os consumidores, sejam eles locais ou globais.

Como estrutura, este artigo apresenta inicialmente um capítulo destinado a contextualização do termo Cultura. Em um segundo momento, tem-se por objeto a Moda, conceituando-a e demonstrando suas origens e instâncias. A posteriori, o Cross-Cultural Design, tema central do estudo, é exposto, no qual abordam-se concepções fundamentais para a construção do termo e seus significados. Em sequência, disserta-se sobre as aplicações do Cross-Cultural Design na projetação de produtos, relacionando-os ao desenvolvimento de produtos de moda. Por fim, apresentam-se as considerações finais, expondo as conclusões obtidas após a compilação deste estudo.

\section{CULTURA}

O ser humano é essencialmente um ser de cultura. Sua evolução, iniciada há aproximadamente quinze milhões de anos, consistiu essencialmente da passagem de uma adaptação genética ao meio ambiente natural para uma adaptação cultural. Ao longo desse processo de hominização, os instintos foram sendo substituídos, progressivamente, pela cultura, ou seja, por esta adaptação criada e controlada pelos homens, muito mais flexível e transmissível, do que a adaptação genética. A cultura é o que permite ao homem se adaptar ao meio, assim como adaptar este meio ao próprio homem, às suas necessidades e aos seus projetos (CUCHE, 2002).

A compreensão da cultura torna-se preocupação de estudiosos no momento em que os contatos entre povos e nações se intensificam. A constatação da existência de uma grande variedade de modos de vida entre diferentes povos tornou-se fundamental estímulo nos debates sobre a cultura. Porém, reflexões sobre a questão existem de longa data, procurando explicações para a existência de costumes, de modos de vida, de crenças e de práticas tão diferentes entre os povos. Indagações sobre esses temas podem ser encontradas em escritos antigos de origem Grega, Romana e Chinesa (SANTOS, 1983).

Já as questões de ordem sistemática com relação à cultura passam a ser formuladas em um tempo mais recente, a partir do século XVIII, na Alemanha. A cultura torna-se preocupação de pensadores interessados na interpretação da história humana, na compreensão de suas particularidades, costumes e crenças. Dessa maneira, os estudos consolidaram o pensamento moderno relacionado à cultura, procurando, de forma sistemática, assimilar a diversidade de maneiras de viver que haviam sido motivo de reflexões por séculos (SANTOS, 1983).

O conceito de cultura torna-se, a partir de então, amplamente discutido por autores de áreas diversas, atrelando-se, por vezes, à ideia de desenvolvimento, e por outras se confundido com a de civilização (BELCHIOR; RIBEIRO, 2014). Couceiro (2002) explana que a conceituação da palavra cultura é, em certa medida, polêmica, visto as suas inúmeras transformações e ampliações ao longo dos decênios, por antropólogos, historiadores e outros intelectuais, o que gera certa dificuldade e imprecisão em sua compreensão.

Do ponto de vista etimológico, cultura é a transposição direta do termo em latim "culturam”, cujo significado é o cultivo ou o cuidado de alguma coisa, como solo, grãos ou animais (GIULIANO, 2013; HILL, 2006; BELCHIOR; RIBEIRO, 2014). Entre antigos pensadores romanos, esse significado foi atrelado à ideia de refinamento pessoal, e está presente, por exemplo, na expressão "cultura da alma", indicando refinamento, sofisticação pessoal, educação elaborada, e assim é empregada até os dias atuais (SANTOS, 1983). 
No século XVI, o sentido de "cultivo" dado ao termo cultura transferiu-se da esfera agrícola para a humana, sendo definida como um processo de desenvolvimento mental. Somente entre os séculos XVIII e XIX, cultura passa a designar um processo geral ou o produto desse processo. Modernamente, dentre outros conceitos, privilegia-se o que concebe a cultura como o estudo da constituição significativa e da contextualização social das expressões linguísticas, ações, gestos, obras de arte, entre outras (HILL, 2006).

Tylor, de acordo com Rodrigues (2008), foi o primeiro a postular que cultura, ou civilização, em seu amplo significado etnográfico, é "o conjunto complexo que inclui conhecimento, crença, arte, moral, lei, costume e quaisquer outras habilidades ou hábitos adquiridos pelo homem como membro de uma sociedade" (RODRIGUES, 2008, p. 23). Para Tylor, a cultura é a expressão da totalidade da vida do homem e caracteriza-se por sua dimensão coletiva. Portanto, ela é adquirida e independe da hereditariedade biológica dos homens, e por ser adquirida, sua origem e seu caráter são, em grande parte, inconscientes (CUCHE, 2002).

A partir do século XX novas formulações sobre o conceito são elaboradas, dando início à construção das teorias modernas sobre cultura. Entre elas, pode-se citar a compreensão da cultura como um sistema simbólico, teoria elaborada principalmente pelo antropólogo Clifford Geertz. Para o autor, a cultura deve ser considerada como um conjunto de mecanismos de controle, regras, planos, instruções, para governar o comportamento, compreendendo que todos os homens são geneticamente aptos para receber um programa, e que este programa seria a cultura (LARAIA, 2014).

Maristela Ono (2008) comenta que para Geertz, a "cultura consiste na teia de significados tecida pelas pessoas na sociedade, a partir da qual desenvolvem seus pensamentos, valores e sua conduta, e analisam o significado de sua própria existência" (ONO, 2008, p. 72). A cultura encontra-se vinculada ao processo de formação das sociedades que, em uma relação de simbiose, dinâmica e interdependente, acompanha o desenvolvimento dos indivíduos e dos grupos sociais.

Geertz (2008) defende a posição de que o conceito de cultura é essencialmente semiótico, sendo a cultura não uma ciência experimental em busca de leis, mas sim, uma ciência interpretativa, à procura de significados. $\mathrm{O}$ autor compreende a cultura como sistemas entrelaçados de signos (ou símbolos) interpretáveis, não a vendo como algo ao qual podem ser atribuídos casualmente os acontecimentos sociais, os comportamentos, as instituições e os processos. Portanto, a cultura é um contexto, algo dentro do qual os elementos podem ser descritos de forma inteligível e com densidade. Desta forma, a abordagem semiótica da cultura tem como fundamento auxiliar na compreensão do mundo conceitual no qual vivem os sujeitos, de modo a permitir, em amplo sentido, dialogar com esses sujeitos.

Através de estudos como o de Clifford Geertz, a partir da segunda metade da década de 1970, o conceito de cultura, integrado ao conjunto de símbolos e significados, tornou-se dominante. A cultura, portanto, passa a ter seu conceito como essencialmente semiótico (RODRIGUES, 2008).

Belchior e Ribeiro (2014) trazem a definição de Thompson (2002) da concepção simbólica da cultura:

Cultura é o padrão de significados incorporados nas formas simbólicas, que inclui ações, manifestações verbais e objetos significativos de vários tipos, em virtude dos quais os indivíduos comunicam-se entre si e partilham suas experiências, concepções e crenças. A análise cultural é, em primeiro lugar e, principalmente, a elucidação desses padrões de significado, a explicação interpretativa dos significados incorporados às formas simbólicas (THOMPSON, 2002, p. 176 apud BELCHIOR; RIBEIRO, 2014, p. 20). 
Em consonância ao pensamento de Thompson (2002 apud BELCHIOR; RIBEIRO, 2014), Ono (2008) configura a natureza, o desenvolvimento e a cultura do ser humano como processos inseparáveis. É a partir dessa fundamental relação que emergem os símbolos, a linguagem, a comunicação, os valores e os modos de viver e de se relacionar das pessoas na sociedade.

A cultura, portanto, pode ser compreendida como um conjunto complexo e abrangente de conhecimentos desenvolvidos pelos homens através dos tempos, incluindo a arte, a moral, as leis, os costumes entre outros, e partilhados em meio aos grupos sociais. Esse conjunto complexo representa um código de símbolos inconscientes que trazem significado a vida dos seres humanos, consistindo em tudo aquilo que o indivíduo tem de conhecer ou acreditar para operar de maneira aceitável dentro de sua sociedade (CUCHE, 2002).

Assim sendo, a cultura, enquanto produto da dinâmica social, relaciona-se com a humanidade como um todo, da mesma forma como está relacionada com cada grupo humano em particular. Isto se deve em função das especificidades em que cada sociedade trata a sua conexão com o mundo real e com o seu ideal imaginário, permeando as práticas cotidianas e as tradições que são passadas entre as gerações (BOSI, 2002).

Todo ser é essencialmente um ser de cultura, e, por isso, herdeiro de um longo processo de acumulação, que reflete o conhecimento e a experiência adquiridos pelas numerosas gerações que os antecederam. Esse caráter acumulativo da cultura permite aos indivíduos a transmissão de experiências e conhecimentos de geração para geração, criando assim um interminável processo de acúmulo de aprendizagem, que beneficia toda a espécie (LARAIA, 2014).

Desta forma, pode-se assimilar que a cultura não é apenas uma referência de uma determinada civilização, mas também o modo de um grupo, sociedade, país ou indivíduo, de viver, de pensar, de classificar e até mesmo de mudar o mundo e a si próprio. Cultura é o aparato de conhecimento produzido que caracteriza um indivíduo e o seu grupo, e as suas relações com o mundo ao seu entorno.

\section{MODA}

A moda pode ser compreendida como um fenômeno social legitimado pelo coletivo, de mudanças cíclicas dos costumes e dos hábitos, dos gostos e das escolhas (CALANCA, 2008). Consoante Palomino (2003), a etimologia da palavra "moda" possui origem do latim modus, correspondente a "modo", "maneira". Da mesma forma, o termo fashion, em inglês, é uma adaptação da palavra francesa façon, utilizada para expressar "modo", "maneira".

Calanca (2008), ao conceituar a palavra "moda", relaciona-a ao termo "costume", determinado como um hábito constante que define o comportamento, o modo de ser de um grupo social, remetendo esta acepção ao conceito de sistema, estrutura, como um conjunto de vários elementos combinados entre si. Para a autora, esses elementos quando isolados, estão privados de valor, porém, quando ligados por um conjunto de normas e valores, assumem um significado. Nesse sentido, Calanca manifesta que o costume se refere essencialmente a uma escala de valores ideais compartilhados por membros de um determinado contexto histórico-social e cultural, os quais tendem a se assemelhar ao máximo. Portanto, a moda é um fenômeno de costume, no momento em que a "paixão" pelo novo, pelo recente, e a renovação das formas torna-se um valor, uma norma coletiva, um hábito. A moda existe quando a necessidade do novo se torna uma exigência cultural.

Lipovetsky (2009) considera a moda como uma forma específica de mudança social, independente de objetos, pois antes de tudo, ela é um mecanismo social, caracterizado por um breve período de tempo e por mudanças ditadas pelo capricho, que afetam diversas esferas da vida coletiva. $\mathrm{O}$ 
filósofo e sociólogo Georg Simmel (2008), compartilha do mesmo pensamento, ao distinguir o fenômeno moda de outros objetos, no caso, a vestimenta, pois a moda é uma manifestação social ampla, que se aplica em todas as arenas sociais, e o vestuário é apenas um dos objetos em que a moda é refletida. Svendsen (2010) complementa que a moda pode ser distinguida em duas categorias principais, como vestuário ou como mecanismo, e aponta que dificilmente se pode conceber algum fenômeno social que não tenha sido influenciado por mudanças da moda, sejam eles a forma do corpo, o design de automóveis, a política ou a arte.

Para Simmel (2008), a essência da moda consiste no fato de que enquanto somente uma parcela do grupo a pratica, a grande maioria dos demais estão a caminho dela. $\mathrm{O}$ caráter cíclico da moda caracteriza-se pela sua expansão e imediata queda, ab-rogando a possibilidade da diferença e, determinando, desta maneira, o fascínio do simultâneo começo e fim, o encanto pela novidade e, consequentemente, pela efemeridade. O efêmero na moda é apontado igualmente por Freitas (2005), ao expor que é exatamente devido ao caráter provisório da moda, que ela consegue se inserir constantemente em um auto processo de renovação.

Souza (1987) esclarece que a moda não é um fenômeno universal, mas sim, característico de determinadas sociedades e épocas. Seu surgimento vai ao encontro do período do Renascimento, momento em que as cidades se expandem e a vida das cortes passa a se organizar, acentuando, no Ocidente, o interesse pelo traje e a aceleração do ritmo das mudanças. A aproximação das pessoas na área urbana estimula o desejo de competir e o hábito de imitar. Anteriormente a esse período, Svendsen (2010) afirma que o vestuário europeu pouco havia mudado da era romana até o século XIV e que mesmo havendo algumas variações nos materiais e nos detalhes das roupas, a forma permaneceu praticamente inalterada. Para considerar as mudanças como moda, elas não podem ocorrer em tempos muito esparsos, pois a moda configura-se essencialmente quando a mudança é buscada por si mesma, de maneira frequente.

Conforme Lipovetsky (2009), a moda é um sistema de regulação e de pressão social, pois as mudanças são acompanhadas de um dever de adoção. Devido ao desejo de imitação dos indivíduos, de se assemelharem àqueles que lhes são superiores, que os decretos da moda conseguem se propagar, essencialmente de cima para baixo, do superior ao inferior. A imitação do vestuário usado pela nobreza difundiu-se nas novas camadas sociais da média e pequena burguesia, surgidas entre os séculos XVI e XVII.

No momento em que as classes inferiores passam a se apropriar do vestuário das classes nobres, ultrapassando a fronteira instituída pelos superiores, que visavam a sua diferenciação dos demais integrantes da sociedade, estes elaboram novos indumentos, com o intuito de se diferenciarem novamente. Desta forma, o jogo de imitações se inicia mais uma vez, alimentando o ciclo da moda (LIPOVETSKY, 2009). Simmel (2008) explica que a instância da moda, enquanto indumentária, é a forma mais acessível para as classes inferiores praticarem a imitação e sentirem-se igualados aos seus superiores.

De acordo com Svendsen (2010) ainda que o nascimento da moda possa ser datado de meados do século XVI, seria mais correto considerar, de acordo com o sentido moderno da moda, de mudanças rápidas e de desafio constante dos indivíduos de se manterem atualizados, que ela se torna uma força real na sociedade a partir do século XVIII, quando a emergente burguesia disputa poder com a aristocracia. Já Souza (1987) pondera que é no século XIX, quando os privilégios de sangue são anulados, que a moda se dispersa por todas as camadas, acelerando as variações dos estilos, mutáveis em espaços de tempo cada vez mais breves. Crane (2009) considera da mesma forma, que as roupas 
somente foram democratizadas durante o século XIX, quando todas as classes sociais passaram a adotar modelos semelhantes de vestuário.

A história aponta que a partir do momento em que a moda pôde ser identificada como um sistema, ela passou a conquistar todas as esferas da vida social, influenciando comportamentos, gostos, ideias, artes, móveis, roupas, objetos e linguagem (CALANCA, 2008). Portanto, nota-se que as instâncias da moda permitem observar a natureza do homem, suas mudanças e transformações através dos tempos.

Este caráter social da moda é observado de forma cada vez mais evidente, permitindo que se afirme que a moda exprime o espírito de um tempo, e de que é um dos mais imediatos sinais de transformação política, social, econômica e cultural. Ela é a expressão ampliada e superficial de uma profunda modificação da vida social (CONTI, 2008).

A moda nos dias atuais, como expõe Conti (2008), parece ser uma representação de um fenômeno de massa que através de complexas dinâmicas contribui para narrar a evolução do costume, das ideias e dos comportamentos coletivos. A moda representa a imagem que a sociedade dá a ela, sendo percebida como diferença absoluta entre o que somos e o que gostaríamos de ser.

Portanto, pode-se descrever o fenômeno da moda como um sistema caracterizado pela efemeridade, pela mudança constante, que acompanha o indivíduo em seus modos de se vestir e de se apresentar perante o mundo. A moda interliga o simples ato de se vestir a um contexto amplo e complexo, cultural, social, político e econômico, e através de suas instâncias, pode caracterizar e descrever as escolhas e caminhos do homem no decorrer da sua história, seja individualmente, seja coletivamente.

\section{CONCEITUANDO O CROSS-CULTURAL DESIGN}

Atualmente, um grande desafio é posto às práticas de design: a compreensão da cultura no desenvolvimento de novos projetos. O mundo é hoje multicultural e as tecnologias atuais devem estar preparadas para atender a variedade de usuários locais de uma forma global, tanto no que tange a conceber tecnologias direcionadas para culturas específicas, quanto para oferecê-las a consumidores de diversas origens culturais, concomitantemente (SUN, 2012).

Para tanto, indagações surgem frente aos novos desafios: Como pode uma tecnologia ser concebida para ser utilizada por usuários culturalmente diversos? Como pode uma tecnologia atingir tanto grupos culturais e ao mesmo tempo dialogar e ter sentido para usuários locais? Como se pode encontrar um equilíbrio entre o ethos cultural local e a subjetividade individual em um projeto? E ainda, como é possível desenvolver projetos que possuam um apelo de design para um contexto local, sem que a cultura dessa comunidade se torne estereotipada nos produtos? Todos esses desafios, e muitos outros, estão sendo refletidos por pesquisadores e profissionais, com o intuito de se desenvolver uma abordagem eficaz para projetar produtos que atendam às expectativas culturais diversas, que apoiem os seus contextos e que valorizem suas identidades (SUN, 2012).

Este panorama descreve as intenções e as preocupações contidas nos ideais do conceito de CrossCultural Design. Parte, portanto, do princípio de que devem ser compreendidas as diferenças culturais para que estas sejam aplicadas aos métodos de design centrados nos indivíduos consumidores e em culturas-alvo. A demanda e as oportunidades para a aplicação do Cross-Cultural Design estão crescendo consideravelmente frente à globalização e a consequente expansão de mercados das empresas, ultrapassando assim, fronteiras nacionais e culturais (SUN, 2012). 
O Cross-Cultural Design, consoante Sun (2012), apresenta uma filosofia de design inovador, com a possibilidade de se criar tecnologias para diferentes culturas, com linguagens e posições econômicas ímpares, garantindo a usabilidade e a experiência dos usuários através das fronteiras culturais.

Walsh e Helkiö (2009) apontam três tendências fundamentais que levaram a necessidade de constituição do conceito do Cross-Cultural Design. O primeiro processo é o de globalização, que teve como consequência a transformação de negócios e processos para que fosse possível dar suporte aos clientes localizados em todas as partes do mundo, em qualquer idioma, país ou cultura. Em decorrência da globalização, formaram-se os demais processos, o de internacionalização e o de localização. No primeiro, passou a se projetar e desenvolver produtos livres de quaisquer atributos específicos da cultura, para que eles pudessem ser facilmente localizados. Já o segundo, consiste na necessidade de se realizar devidas alterações de design para que os produtos sejam culturalmente e tecnicamente adequados para a cultura de destino.

Os designers têm percebido a importância em associar características culturais nos produtos, através do estudo aprofundado de culturas locais como estratégia de inovação. O campo do design tem desempenhado importante papel neste processo de incorporação dos elementos culturais em produtos, e no aumento do seu valor cultural, com o intuito de inseri-los competitivamente junto ao mercado global. Pode-se afirmar que a concepção de produtos com características locais, a fim de enfatizar seu valor cultural, em um mercado global é, atualmente, uma questão crítica nos processos de design (LIN, 2007).

\section{A MODA E O DESENVOLVIMENTO DE PRODUTOS CULTURAIS}

O Cross-Cultural Design é consideravelmente recente e estudos que o relacionem às esferas da indústria da moda não foram encontrados nas fontes pesquisadas. Porém, muitas relações entre essas duas temáticas, que parecem ser tão relevantes nos tempos vividos, podem ser formuladas.

A moda, consoante Lipovetsky e Seroy (2011), está se encaminhando para uma maior valorização das identidades dos sujeitos, buscando novas relações entre as sociedades locais e globais, resignificando, através dos seus objetos de consumo, as culturalidades do contemporâneo.

A discussão sobre a diversidade cultural como expressão de identidade é fundamental para o entendimento do papel do design no desenvolvimento de produtos para as sociedades, diante dos imperativos de padronização e diversificação e da questão local e global que remetem à dialética entre a uniformização cultural e a diversidade de identidades, no contexto da cultura material (ONO, 2006, p. $3)$.

Novas formas na concepção do trabalho do designer estão sendo notadas no panorama atual. O design tem se tornado uma disciplina fundamental para a sociedade, e os criadores estão começando a refletir e a responder a questões que podem ser consideradas como morais da profissão. Um novo modelo de design, mais centrado nos indivíduos, na humanidade e no planeta, está emergindo, e levando os designers a repensarem práticas e projetos em longo prazo (BEZERRA, 2008).

Frente a esta tendência emergente, despontam pesquisas voltadas ao design com vistas a atender a valorização cultural e a inserção de características locais no desenvolvimento de novos produtos, como o pesquisador Lin (2007) que, fundamentado em estudos anteriores dos autores Moalosi, Popovic e Hudson (2004), Wu, Hsu e Lin (2004), K. Lee (2004) e Leong e Clark (2003), propõe uma estrutura para embasar o estudo de objetos culturais. O material por ele apresentado estabelece um modelo de Cross-Cultural Design capaz de proporcionar aos designers uma ferramenta valiosa para a concepção de um produto cultural bem-sucedido. 
O modelo proposto por Lin (2007) e exposto na Figura 1, apresenta a cultura estratificada em três camadas, representadas verticalmente nos quadros em tons de verde, sendo elas: (1) Física ou Material, onde se inclui alimentação, vestuário, objetos, entre outros; (2) Social ou Comportamental, englobando relacionamentos humanos e organização social; e (3) a Cultura Espiritual ou Ideal, incluindo arte e religião, por exemplo.

Figura 1 -Três Camadas e Níveis da Cultura e Características de Design

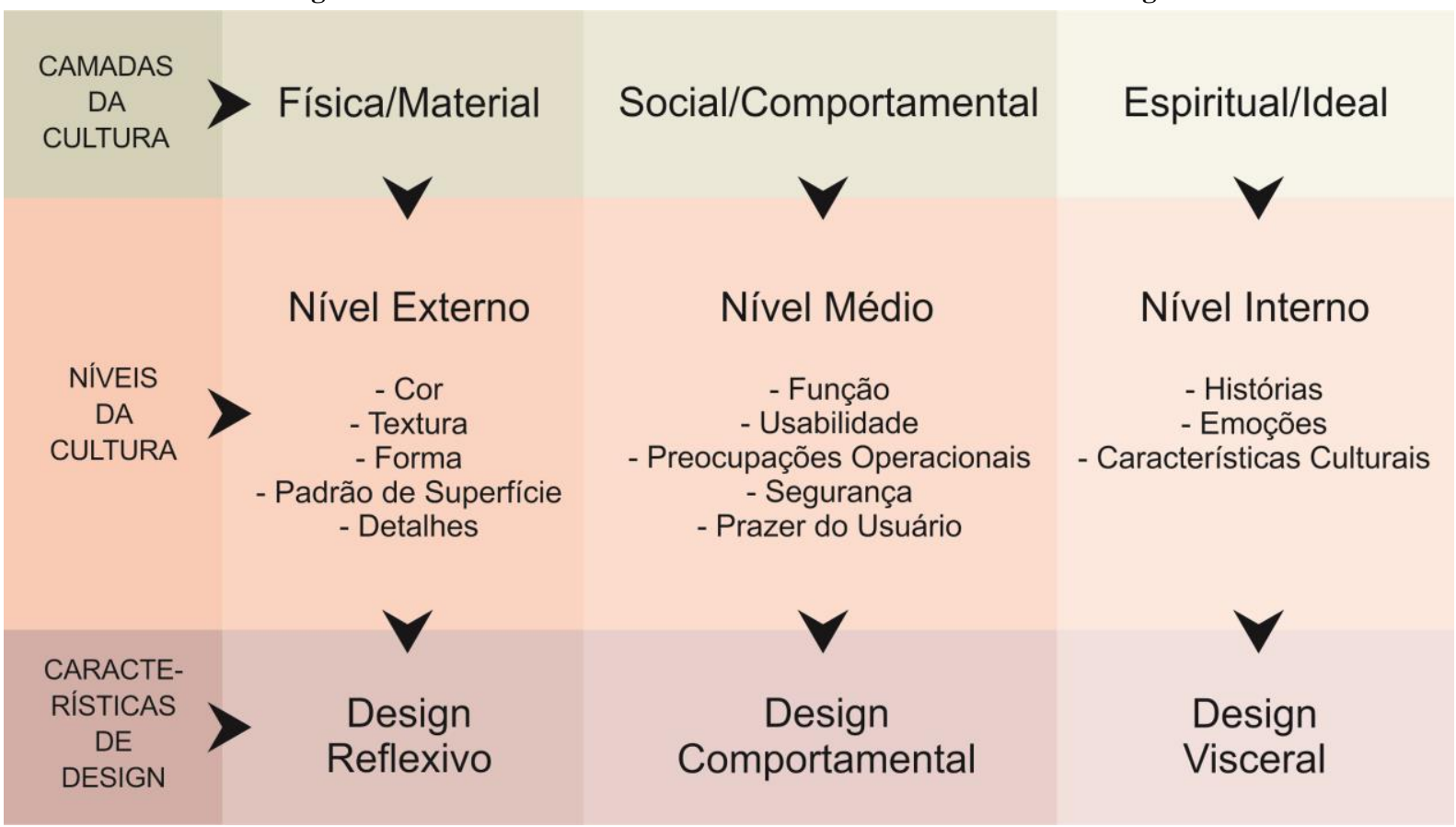

Fonte: Elaborado pelos autores, 2017, adaptado de Lin (2007)

Essas três Camadas da Cultura interligam-se a três Níveis Culturais, que refletem a estética, a função e os símbolos, representados na Figura 1 pela linha em tons de bege, denominadas como: (1) Nível Externo, também considerado como "tangível”; (2) Nível Médio, ou "comportamental”; e (3) Nível Interno, classificado como "intangível".

Nesses Níveis da Cultura, é possível incorporar três Características de Design, onde a Nível Externo tem-se o Design Reflexivo, em que se podem analisar aspectos "tangíveis" ou "estéticos" de artefatos de determinada cultura, tais como cor, textura, formas, padrões de superfície e detalhes. $\mathrm{O}$ Nível Médio correlaciona-se ao Design Comportamental, onde se podem citar a função, a usabilidade, as preocupações operacionais, a segurança e o prazer do usuário. E por fim, o Nível Interno, relacionado ao Design Visceral, interliga-se a aspectos "intangíveis", lidando com símbolos, e pode ser analisado com base na história, nas emoções ou em outras características culturais (LIN, 2007).

Para que a transferência de características de uma cultura para um produto cultural seja realizada de maneira adequada, Lin (2007) propõe um quadro no qual relaciona os Níveis e as Camadas da Cultura com as Características de Design, com o intuito de melhor ilustrar o processo de concepção do CrossCultural Design, como segue na Figura 2. 
Figura 2 - Modelo de Design de Produto Cultural

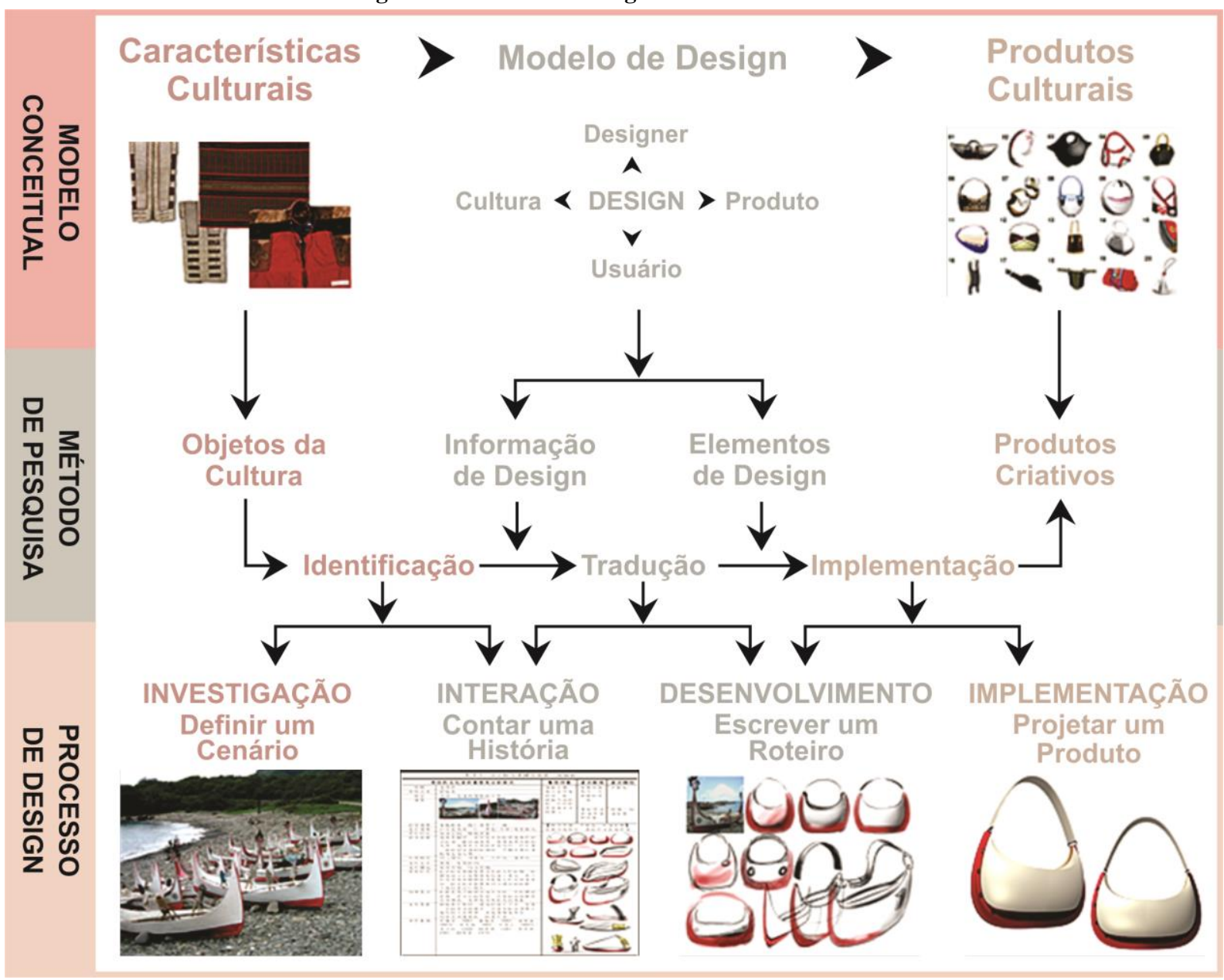

Fonte: Elaborado pelos autores, 2017, adaptado de Lin (2007)

O modelo que apresenta o Processo de Design para o desenvolvimento de um produto cultural, exposto na Figura 2, consiste em três fases principais: o Modelo Conceitual, o Método de Pesquisa e o Processo de Design.

O Modelo Conceitual se concentra em como extrair características culturais de um artefato de determinada cultura para em seguida transferi-las para um Modelo de Design. De acordo com Lin (2007) esse Modelo de Design consiste em três etapas, conforme exposto na Fase de Método de Pesquisa, sendo elas:

1. Identificação: As características culturais são identificadas e extraídas de um objeto cultural original, incluindo o estudo do Nível Externo (cor, textura e padrão), do Nível Médio (função, usabilidade e segurança), e do Nível Interno (emoção, significado cultural e histórias). Através desse processo de Identificação, o designer, utilizando o método científico e outros métodos de investigação, pode obter informações de design a partir de um objeto cultural para, posteriormente, avaliar e utilizar as informações coletadas.

2. Tradução: Nesta fase ocorre a transformação das características culturais obtidas a partir de um objeto cultural original em conhecimento de design. Nesse processo, o designer consegue profundidade e experiência prática em relação a essas características de design, ao mesmo tempo em que é capaz de relacionar esses conhecimentos de design para projetar produtos que atentam para os problemas e anseios da sociedade moderna, estimulando a interação entre cultura, tecnologia e sociedade.

3. Implementação: Esta fase envolve expressar o conhecimento de design associado às características culturais. Aqui é manifestada a compreensão do designer acerca do significado da cultura, 
bem como a sua sensibilidade estética e a sua flexibilidade para se adaptar a uma diversidade de projetos. Nesta etapa do processo, o designer adquire conhecimento sobre um artefato cultural e compreende o espectro da cultura e dos valores relacionados a esse objeto original da cultura. $\mathrm{O}$ designer combina este conhecimento com o seu senso de design, a fim de lidar com questões de design e de empregar todos os níveis das Características Culturais na concepção de um produto cultural.

A última fase exposta na Figura 2 concentra-se no Processo de Design, onde o produto cultural é projetado utilizando como recursos o "cenário" e o "story-telling", ou "contar histórias". São identificadas nessa terceira e última fase, quatro etapas, que seguem elucidadas abaixo:

1. Investigação / Definir um Cenário: $O$ primeiro passo consiste em encontrar as principais características culturais no objeto original da cultura em estudo, para posteriormente se definir um cenário que se encaixe nos três níveis já referenciados na Figura 1: Nível Externo (Tangível), Nível Médio (Comportamental) e Nível Interno (Intangível). Alicerçado nas características culturais, o cenário deve considerar o ambiente global em que o produto é consumido, incluindo questões econômicas, sociais e aplicações tecnológicas. Nesta etapa o designer analisa as características culturais do objeto a fim de estabelecer as principais características culturais que podem ser aplicadas para representar o novo produto a ser projetado.

2. Interação / Contar uma História: A partir do cenário definido na etapa anterior, passa-se a observação do usuário, a fim de explorar o ambiente sociocultural, com vistas a conceber um produto que tenha um estilo e significado cultural derivado de um objeto cultural original. Desta forma, algumas interações devem ser exploradas nessa etapa, incluindo a interação entre cultura e tecnologia, o diálogo entre usuários e designers, assim como a compreensão das necessidades do usuário e do ambiente cultural. De acordo com essas interações, uma abordagem centrada no usuário com base na narração de histórias é desenvolvida para descrever as necessidades do usuário e as características do produto a ser criado.

3. Desenvolvimento / Escrever um Roteiro: Nesta etapa concentra-se o desenvolvimento do conceito e do design do produto. Aqui se realiza um esboço da ideia, em forma de texto e imagem gráfica, baseados no cenário definido e nas histórias contadas. Durante essa etapa, pode ocorrer a necessidade de se fazer modificações no cenário e na história, com a intenção de ter ao final do processo um produto com significado cultural. Neste momento de desenvolvimento, confirma-se as necessidades do usuário por determinado produto e estabelece-se a forma como o produto será projetado para atender à essas necessidades.

4. Implementação / Projetar um Produto: A última etapa reúne as características previamente identificadas no contexto do produto cultural. Neste momento, todos os recursos culturais devem ser listados em uma tabela, servindo de ferramenta para auxiliar o designer a verificar as características culturais que serão aplicadas no processo de design. Neste momento final são avaliadas as características selecionadas, adequando-as ao novo produto. É possível ainda realizar algumas alterações e implementações no protótipo, com base na avaliação das características culturais.

Este modelo apresentado por Lin (2007) fornece um meio eficaz para projetar produtos que atentem à valorização da cultura e é visivelmente possível de ser incorporado nos processos de criação e desenvolvimento de produtos de moda, sejam eles vestuário ou acessórios.

De acordo com Moretti (2008), a moda está atualmente inserida em um mercado global de aceleradas transformações, o qual demanda a formação de profissionais qualificados e capazes de comunicar e compreender diferentes realidades culturais e econômicas. Conforme Ono (2006), o âmbito do design envolve planejamento, a seleção de modos, de pensamentos e de valores, atribuindo ao 
designer a co-responsabilidade pelas relações que se estabelecem entre os produtos que o mesmo desenvolve e as pessoas, bem como, pelas implicações destes artefatos na sociedade.

O Cross-Cultural Design visa o desenvolvimento de um produto inovador que satisfaça os consumidores de uma determinada sociedade, tanto culturalmente, quanto esteticamente (HO et al., 2006 apud LIN, 2007). A partir da utilização de recursos culturais para agregar valor a novos produtos, beneficia-se não somente o crescimento econômico de um grupo social, como também, promove a singularidade de uma cultura local a nível global de mercado (LIN, 2007).

É de fundamental importância para o papel do designer, seja qual for a sua área específica de atuação, a compreensão das funções que os objetos assumem na vida das pessoas dentro dos seus contextos socioculturais. Os designers devem, a partir desse entendimento, desenvolver conceitos e suportes materiais que traduzam as necessidades e os aspectos da diversidade cultural dos indivíduos e das sociedades (ONO, 2006).

\section{CONSIDERAÇÕES FINAIS}

O panorama do mundo contemporâneo, globalizado e multicultural, modifica e interfere diretamente a vida dos indivíduos no que tange às suas relações e práticas de consumo, bem como influencia a concepção de novos produtos, que devem passar a atender aos anseios modernos. Neste ínterim, torna-se imperativo para a área do design a criação de produtos que sirvam de aporte para a valorização cultural, que traduzam as necessidades e os aspectos da diversidade cultural dos indivíduos e das sociedades.

A moda, como parte integrante da produção cultural das sociedades, pode ser claramente considerada fonte de inspiração e um meio para a valorização das culturas e identidades em seus projetos, sejam eles vestuário ou acessórios. Neste ínterim, o conceito de Cross-Cultural Design emerge como uma ferramenta de auxílio aos designers na concepção de produtos que atentem à multiplicidade das culturas, respeitando e considerando aspectos de sentido primordial para os consumidores, sejam eles locais ou globais.

Frente ao mundo contemporâneo, unido através da informação e das trocas comerciais, torna-se imperativo este desafio posto aos designers, o de desenvolver produtos que atentem à subjetividade das culturas, contemplando um apelo de design para um contexto local, sem que a cultura esteja neles estereotipada.

Para tal, os aspectos culturais das regiões as quais os produtos são destinados, necessitam de um estudo aprofundado e sistemático, para que posteriormente possam ser transmutados em ideias originais para a concepção de projetos inovadores. Nota-se que o mercado da moda já está voltando-se para uma maior valorização das identidades, como resposta a uma mudança dos próprios consumidores, que hoje detêm a informação, exigindo produtos com responsabilidade social e ambiental, produtos que realmente façam sentido para suas vidas e que respeitem suas construções subjetivas culturais e históricas.

Com a pretensão de atender a esta necessidade crescente de valorização cultural, o Cross-Cultural Design pode atuar como importante elemento de subsídio à profissão do design. Para que isso seja possível, será necessário um maior aporte de investigação, de estudos e de experimentos da aplicação das ideias deste conceito-chave nos projetos de design, não somente na área do vestuário, como também em todas as demais áreas nas quais o profissional do design atua. 
Ressalta-se, por fim, que no campo de atuação da moda não foram encontrados registros de estudos pertinentes à linha do Cross-Cultural Design, o que torna esta área um campo fértil para novas pesquisas.

\section{REFERÊNCIAS}

BELCHIOR, Camilo; RIBEIRO, Rita A. C. Design \& Arte: entre os limites e as interseções. Contagem: Editora do Autor, 2014.

BEZERRA, Charles. O designer humilde: lógica e ética para inovação. São Paulo: Edições Rosari, 2008.

BOSI, Alfredo. Dialética da colonização. São Paulo: Companhia das Letras, 2002.

CALANCA, Daniela. História social da moda. São Paulo: Senac São Paulo, 2008, 227 p.

CIDREIRA, Renata Pitombo. Os sentidos da moda: vestuário, comunicação e cultura. São Paulo: Annablume, 2005.

CONTI, Giovanni Maria. Moda e cultura de projeto industrial: hibridação entre saberes complexos. In: PIRES, Dorotéia Baduy (org.). Design de Moda: olhares diversos. Barueri: Estação das Letras e Cores, 2008

COUCEIRO, Sylvia. Os desafios da história cultural. In: BURITY, Joanildo A (org.). Cultura e identidade: perspectivas interdisciplinares. Rio de Janeiro: DP\&A, 2002.

CRANE, Diana. A moda e seu papel social: classe, gênero e identidade das roupas. São Paulo: Senac São Paulo, 2009.

CUCHE, Denys. A noção de cultura nas ciências sociais. Bauru: EDUSC, 2002.

FREITAS, Ricardo Ferreira. Comunicação, consumo e moda: entre os roteiros das aparências. Comunicação, mídia e consumo, São Paulo, v. 3, n. 4, p. 125-136, 2005.

GEERTZ, Clifford. A interpretação das culturas. Rio de Janeiro: LTC, 2008.

GIULIANO, Carla Pantoja. A influência da diversidade cultural nos projetos das interações. In: Anais... IX SEPesq, 2013, Porto Alegre. Anais IX SEPesq. Porto Alegre: 2013.

. Cross-Cultural Design no Desenvolvimento de Projetos. In: Anais... XI SEPesq, 2015, Porto Alegre. Anais XI SEPesq. Porto Alegre: 2015.

HILL, Telenia. Homem, cultura e sociedade. Rio de Janeiro: Lucerna, 2006.

JONES, Sue Jenkyn. Fashion Design: manual do estilista. São Paulo: Cosac Naify, 2005.

LARAIA, Roque de Barros. Cultura: um conceito antropológico. Rio de Janeiro: Zahar, 2014.

LIN, Rung-Tai. Transforming Taiwan aboriginal cultural features into modern product design: A case study of a cross-cultural product design model. International Journal of Design. v. 1, n. 2, p. 45-53, 2007. Disponível em: <http://www.ijdesign.org/ojs/index.php/ijdesign/article/view/46/26>. Acesso em: 22 out 2015.

LIPOVETSKY, Gilles. O império do efêmero: a moda e seu destino nas sociedades modernas. São Paulo: Companhia das Letras, 2009. 
LIPOVETSKY, Gilles; SERROY, Jean. A cultura-mundo: resposta a uma sociedade desorientada. São Paulo: Companhia das Letras, 2011.

MANZINI, Ezio; MERONI, Anna. Design em transformação. In: KRUCKEN, Lia. Design e território: valorização de identidades e produtos locais. São Paulo: Studio Nobel, 2009.

MORAES, Dijon de. O papel atual do design. In: KRUCKEN, Lia. Design e território: valorização de identidades e produtos locais. São Paulo: Studio Nobel, 2009.

MORETTI, Mirella. Comunicar e compreender para um desafio global. In: SORCINELLI, Paolo (org.). Estudar a moda: corpos, vestuários, estratégias. São Paulo: Editora Senac São Paulo, 2008.

ONO, Maristela Mitsuko. Design e Cultura: sintonia essencial. Curitiba: Edição da autora, 2006.

. Design e Multiculturalismo: tecitura polissêmica, multidimensional e variável. In: MORAES, Dijon de (Org.). Design e Multiculturalismo. Cadernos de Estudo Avançado em Design, Belo Horizonte, v. 1, p. 71-80, 2008.

PALOMINO, Erika. A moda. São Paulo: Publifolha, 2003.

RODRIGUES, Antonio Greco. Multiculturalismo. In: MORAES, Dijon de (Org.). Design e

Multiculturalismo. Cadernos de Estudo Avançado em Design, Belo Horizonte, v. 1, p. 21-30, 2008.

SANTOS, José Luiz dos. O que é cultura. São Paulo: Brasiliense, 1983.

SIMMEL, Georg. Filosofia da moda e outros escritos. Lisboa: Edições Texto \& Grafia, 2008, 111 p.

SOUZA, Gilda de Mello e. O espírito das roupas: a moda no século dezenove. São Paulo:

Companhia das Letras, 1987.

SUN, Huatong. Cross-Cultural Technology Design: Creating Culture-Sensitive Technology for Local Users (Human-Technology Interaction). Oxford: Oxford University Press, 2012.

SVENDSEN, Lars. Moda: uma filosofia. Rio de Janeiro: Zahar, 2010.

WALSH, Tanja. HELKIÖ, Liino. What is Cross-Cultural Design? In: Cross-Cultural UX Design Seminar, 2009, Finlândia, Slides, Tampere University oh Technology, 2009, p. 1-26. Disponível em: <http://www.cs.tut.fi/ihte/projects/suxes/pdf/TUT_What\%20is\%20cross-cultural\%20design.pdf >. Acesso em: 14 jul. 2015. 